\title{
REMOTE SENSING METHODS FOR ESTIMATION OF URBAN HEAT ISLANDS ON THE EXAMPLE OF KRASNOYARSK CITY
}

\author{
Aleksandra Matuzko ${ }^{1,2}$ \\ Dr. Oleg Yakubailik ${ }^{1,2}$ \\ ${ }^{1}$ Institute of Computational Modelling of the Siberian Branch of the Russian Academy of \\ Sciences (ICM SB RAS), Russia \\ ${ }^{2}$ Siberian Federal University, Russia
}

\begin{abstract}
The temperature at the Earth's surface can be estimated by ground-based methods or satellite remote sensing data. Satellite remote sensing is the only means of obtaining longterm homogeneous series of land surface temperature data. The network of ground-based observations usually is quite rare, so it is important to obtain information by remote methods. From the values of the thermal infrared spectral bands, it is possible to determine the radio brightness temperature of the underlying surface. The compilation of temporal temperature series of the land surface is useful for solving a large number of scientific problems. The information obtained during the survey of the Earth in the thermal range can be used in geographic science in two main directions. In the first case, thermal radiation is an indicator of objects, phenomena and processes that are hidden from direct observation, and in the second case, thermal radiation itself, whose importance is important in climate change matters, is of interest.
\end{abstract}

The paper presents the results of investigations the land surface temperature (LST) anomalies in Krasnoyarsk city (Russia) and its suburban area. The urgency of the task is due to the peculiarities of city with a population of more than a million people, which is situated 40km below the hydroelectric power station (HPS) on the Yenisei river. Due to HPS the Yenisei river running through the city does not freeze even in severe winters, when the ambient temperature may fall below $-30^{\circ} \mathrm{C}$, thus acting as a strong heat and evaporation island. Conversely, in summer the river is unusually cold.

We used information from Landsat 8 satellite, namely Thermal Infra-Red Sensor (TIRS) and Operational Land Imager (OLI) data, which have $100 \mathrm{~m}$ and $30 \mathrm{~m}$ spatial resolution respectively. Ground-based temperature data from the environment protection state regional system for observing the state of the atmosphere in the Earth's surface layer were also used.

The problem of temperature anomalies is typical for all major cities in the world. Space thermal images are a powerful source of information for analyzing and forming temperature anomalies within a single territory. Determination of the nature and boundaries of temperature anomalies will help to understand the causes of the unfavorable ecological situation in Krasnoyarsk city, where, in addition to high industrial emissions, atmospheric processes influence cause impurities to linger and concentrate over the city.

To estimate the land surface temperature it's necessary to define the emissivity. To date, there are a number of different ways to do this. We used the method based on normalized 
vegetative index computation. The main procedure was based on interpretation of Landsat-8 TIR data, with preliminary radiometric and atmospheric correction stage.

Ten cloudless scenes during the snowless period from 2013 to 2016 were considered. Based on the results of the study, thermal anomalies of urban area were formed.

Keywords: urban heat island, thermal infrared imagery, temperature anomalies.

\section{INTRODUCTION}

Temperature, which is one of key indices of natural environment, can be measured by ground-based methods or based on satellite data. In a highly sparse and even shrinking network of ground-based weather stations in recent years, satellite remote sensing is a worthy alternative to traditional methods of temperature measurement, which ensures the production of long-term homogeneous data series for the study area.

Evaluation of land surface temperature by remote sensing methods is based on thermal infrared (TIR) band data. Satellite systems that currently exist allow obtaining TIR band data with different repetitively and resolution level - from daily with spatial resolution of $1 \mathrm{~km} /$ pixel to weekly with resolution of about $100 \mathrm{~m} / \mathrm{pixel}$, the accuracy of temperature measurement is about 1-2 degrees. In that context, Landsat satellite series data appear to be the most attractive due to the combination of its technical characteristics, availability of information, availability of a multi-year archive of observations. Beginning in 2013, Landsat-8 satellite is working in orbit, which is mounted with TIRS scanner, which performs shooting in two bands in TIR range. Registered TIR band data are recalculated to radio-brightness temperature, which then is recalculated into surface temperature. An integral part of final step is the calculation of surface emissivity coefficient.

The subject of the analysis in the work were temperature anomalies in the Krasnoyarsk city, which were estimated from Landsat- 8 satellite data. The task was to identify characteristic temperature inhomogeneity in the city, their spatial location and quantitative assessment. Urban heat island (UHI) is a common term to describe these effects in recent years. The expediency of such studies is due to the fact that they help to understand the causes of the adverse environmental situation in Krasnoyarsk, microclimatic conditions of the urban environment, which in turn are formed under the influence of anthropogenic factors. Krasnoyarsk is a city with a population of more than a million people and a very unfavorable ecological situation; it is one of the most polluted cities in Russia. Analysis and modeling of atmospheric air pollution is complicated by a number of factors-significant unevenness of the terrain within the city, the temperature regime of the Yenisei river that cuts the city in half. In this context, satellite remote sensing methods that are based on TIR band data are of particular interest.

\section{DATA AND METHODOLOGY}

\section{Thermal anomalies and the study area}

In recent years, the relationship between the use of urban land and environmental quality has received increased attention in both research and planning. Built-up areas look like uneven artificial landscapes with building materials, partially different from natural surfaces. In addition, anthropogenic processes release excess heat and pollution to the 
surrounding air. Together they lead to a higher urban temperature compared to a relatively natural environment.

Special attention has begun to be paid to the urban heat islands. The effect of increase of the temperature of the environment is observed in large cities, where the air temperature throughout the year is several degrees higher than in the adjacent areas.

Krasnoyarsk city is a large industrial center with unique natural and climatic features, caused by terrain conditions and thermal heterogeneity of the terrain. Krasnoyarsk is classified as having a high potential for atmospheric pollution. The basin character of the terrain, highly frequent fogs and soaring over the Yenisei lead to accumulation of harmful impurities above the main territory of the city.

Krasnoyarsk is located at the junction of three geomorphological countries: the West Siberian Plain, the Middle Siberian Plateau and the Altai-Sayan Mountainous Country. Krasnoyarsk is located on the two banks of the Yenisei River. Construction of hydroelectric power stations on the Yenisei River, led to no freezing during the cold season. The air temperature in winter reaches values below $-30^{\circ} \mathrm{C}$. The formation of temperature anomalies in the city is affected by the large temperature difference between the nonfreezing Yenisei and the surrounding area.

Thus, the interaction of the two effects of temperature anomalies adversely affects the ecological situation in the city. Therefore, it is so important to observe temperature anomalies at different times of the year., There are sample opportunities for research in this field with use of Earth remote sensing data.

\section{Earth remote sensing data}

The collection of space imagery materials in the thermal infrared range has been accumulating since the 1960s. The USA Landsat program began its existence in 1972, since then, seven satellites were launched. The collected archive of images allows analyzing the changes that have occurred on Earth for more than 40 years. Technologies for obtaining information by remote methods have evolved and methods for estimating the temperature of the land's surface have been developed [1].

The launch of the Landsat- 8 satellite took place in February 2013. Landsat 8 satellite receives data using two different sensors, such as Operational Land Imager (OLI) and Thermal Infrared Sensor (TIRS). The TIRS scanner was created in the NASA Goddard Space Flight Center and is intended for imaging in the far infrared. GaAs-based Quantum Well Infrared Photodetector (QWIP) photodetectors are installed in the focal plane of TIRS [2]. Landsat-8 images consist of 11 spectral bands, where the 10th and 11th are far infrared bands with a spatial resolution of $100 \mathrm{~m}$, which allows them to analyze the energy of the Earth's surface rather than the reflection of sunlight [3].

\section{Evaluation of land surface temperature}

At present, several methods are used to determine the surface radiation coefficient based on satellite data, two of them are considered in the article. The first method uses the result of classification of objects on the image with subsequent assignment of specific values of the radiation coefficient to each object, and in the second it is determined on the basis of the NDVI index. The first method is easier to use, but its accuracy is limited and depends on the effectiveness of the classification results of the image. The second method has a 
higher accuracy and allows calculating the land surface emissivity for each pixel of the image [4].

From the values of the thermal bands, it is possible to determine the radio brightness temperature of the underlying surface. Instead of measuring air temperature, as weather stations do, satellite systems measure the surface temperature, which is often higher. Theoretically, the accuracy of the temperature estimate is about $0.5^{\circ} \mathrm{C}$, however, the haze in the atmosphere understates values by several degrees [5]. The initial data for determining the temperature are the values of the intensity of the radiation coming to the sensor of the satellite and registered by the corresponding thermal band. Based on the values of these thermal bands, we calculate the value of the land's surface temperature using the expression [1]:

$\lambda=$ wavelength of emitted radiance

$\mathrm{c}_{2}=\mathrm{h} * \mathrm{c} / \mathrm{s}=1.4388 * 10^{-2} \mathrm{~m} \mathrm{~K}=14388 \mu \mathrm{m} \mathrm{K}$,

$\mathrm{h}-$ Planck's constant $=6.626 * 10^{-34} \mathrm{~J} \mathrm{~s}$,

$\mathrm{s}-$ Boltzmann constant $=1.38 * 10^{-23} \mathrm{~J} / \mathrm{K}$,

$\mathrm{c}-$ velocity of light $=2.998 * 10^{8} \mathrm{~m} / \mathrm{s}$,

$\mathrm{e}$ - surface emission coefficient,

$T_{B}$ - the At-Satellite Brightness Temperature (K);

The values of the coefficients the emissivity are presented in the table, and they depend on the type of the land's surface (the values used are approximate, since the radiation coefficient of each material must be obtained from the field survey):

Table 1. Correspondence of the land's surface and the value of the emissivity

\begin{tabular}{|l|c|c|c|c|}
\hline Land surface & Bare soil & Vegetation & Built-up & Water \\
\hline Emissivity e & 0.928 & 0.982 & 0.942 & 0.98 \\
\hline
\end{tabular}

The correct determination of the land surface temperature is limited to an accurate knowledge of the emissivity. The emissivity of the surface is controlled by factors such as water content, chemical composition, structure and soil roughness. The relationship between the land's surface temperature and the Normalized Difference Vegetation Index $(N D V I)$ takes into account that vegetation and soils are the main surface coverage for the terrestrial component [6].

$$
e=a+b \cdot \ln (N D V I)
$$

where $\mathrm{a}=1.0094, \mathrm{~b}=0.047$ are obtained by a regression analysis based on a dataset [7]. NDVI is calculated from the values of reflectance of the visible and near infrared bands:

$$
N D V I=\frac{\rho_{N I R}-\rho_{R E D}}{\rho_{N I R}+\rho_{R E D}}
$$

where $\rho_{N I R}-$ the spectral reflectance measurements acquired in the near-infrared regions и $\rho_{R E D}-$ the spectral reflectance measurements acquired in the red (visible) regions. 


\section{Initial data}

As to input satellite data, 10 cloudless scenes from Landsat 8 are used as the materials for investigating the thermal features of the territory of Krasnoyarsk city. These scenes are acquired during the snowless period from 2013 to 2016.

In our work, the application of the first method for calculating the land surface temperature is considered. To implement it, several GIS operations are required, but much less computations than for the implementation of the second method. The land surface temperature is calculated using the values of the 10th Landsat band, which underwent the radiometric and atmospheric correction stage.

The initial data for determining the land surface temperature is the archive of Landsat 8 satellite images. Software: QGIS 2.18.1 with the Semi-Automatic Classification Plugin (SACP) plug-in [8].

\section{RESULTS}

The temperature of the land surface was calculated by formula (1). We convert the obtained temperature values into degrees Celsius and on the basis of the values obtained, we compile a land surface temperature map in the vicinity of the city of Krasnoyarsk. (Fig. 1).

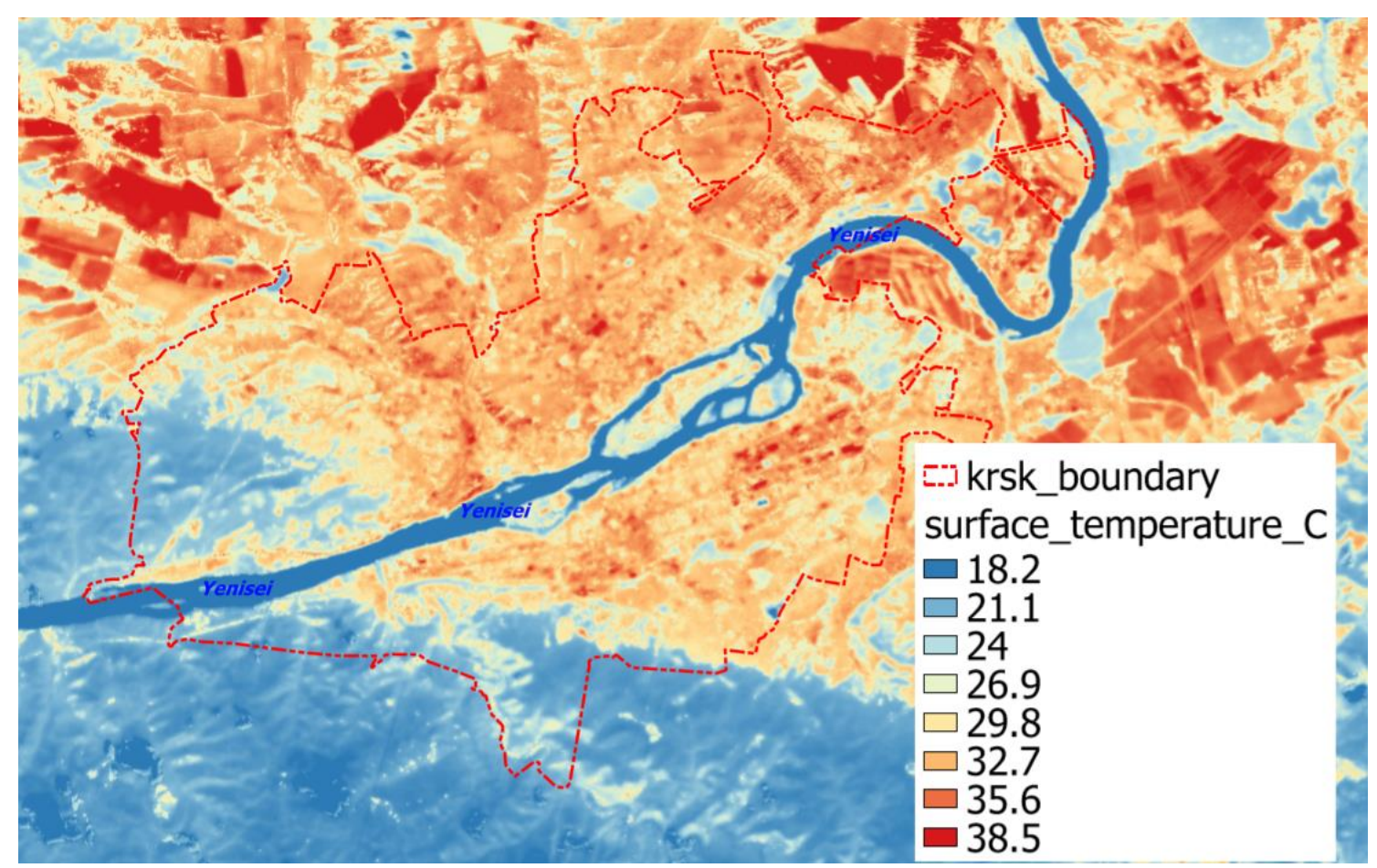

Figure 1. Surface Temperature of Krasnoyarsk city, June 10th 2016

Figure 1 shows that the temperature of the river is much lower than the surface temperature of urban areas, forests and mountains, although in spring in a natural environment the temperature of the water in the river is usually higher than the air 
temperature. The construction of a hydroelectric power station on the Yenisei River, in about $40 \mathrm{~km}$ from Krasnoyarsk, near the city of Divnogorsk, had a great influence on the distribution of seasonal temperatures in the city and its suburbs [9].

Changes in the thermal regime of the river as a result of the construction of hydraulic structures in comparison with natural conditions affect the work of not only the hydropower plant itself, but also water management facilities, water transport, and water and climate quality. Thus, downstream of the hydroelectric power plants, regardless of the period of the annual cycle, the characteristic changes in water temperature occur.

Specifically, the water temperature in the Yenisei in the city area in the summer is $8-10^{\circ} \mathrm{C}$ lower than before the regulation of the river, and, conversely, it increases by $4-5^{\circ} \mathrm{C}$ in the autumn months, which created certain difficulties in the development of the adjacent territory and had a significant influence on the climate of Krasnoyarsk city [10].

To cut off artifacts on the land surface, which can locally influence results of calculations. We average the values of the obtained temperature values to $100 * 100$ meters. Having obtained a temperature map of Krasnoyarsk city of, in Figure 2 you can see the warmest parts of the city. Compare the location of these sites for the ten images discussed earlier.

To find the maximum temperature values within the city, all the images were divided into three seasons: summer, spring and autumn. To determine the maximum temperature values, six summer images were considered (Fig. 2)

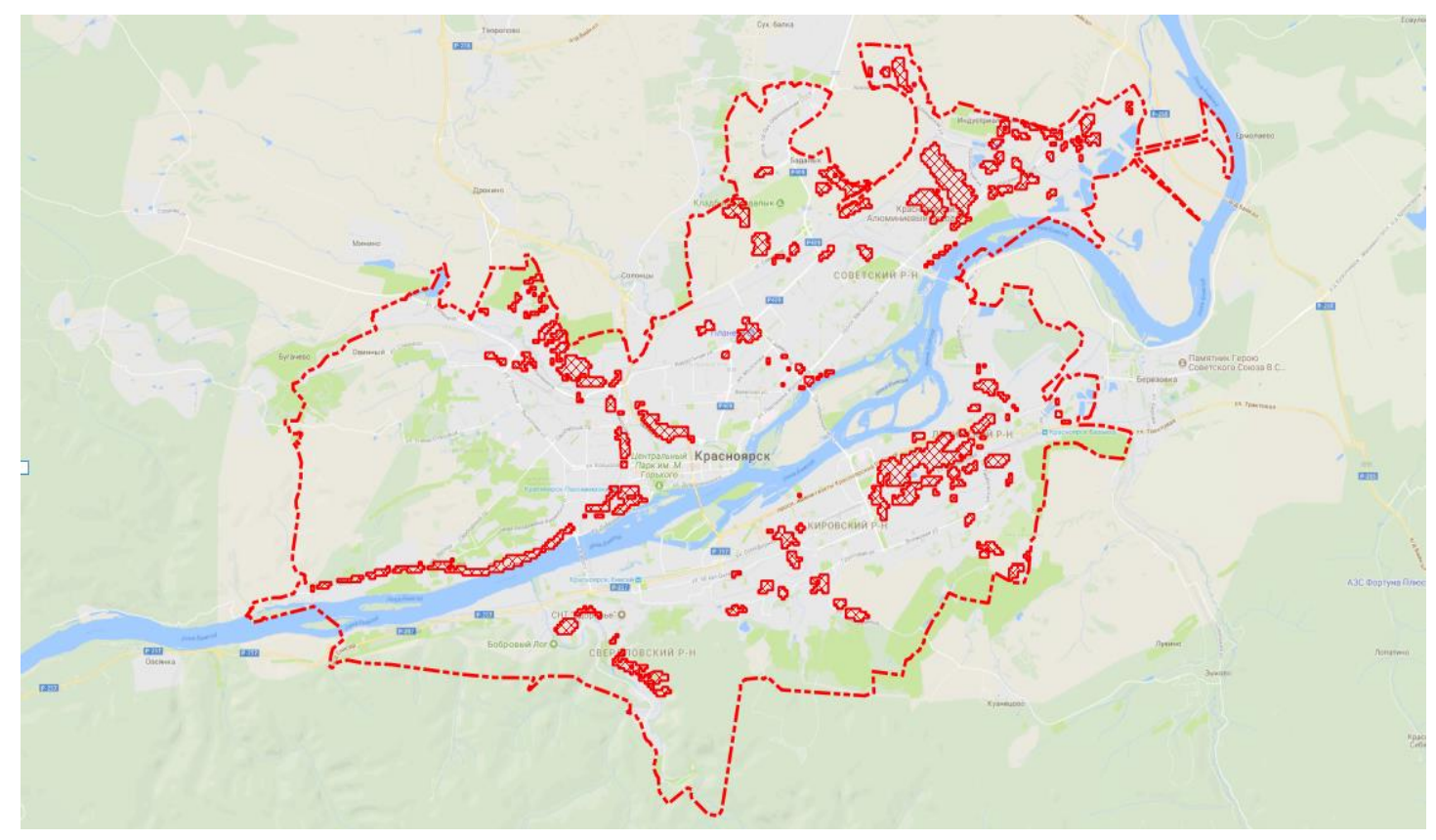

Figure 2. Distribution of maximum temperature values in summer

The temperature in the places of temperature anomalies is 5-8 degrees higher than the average surface temperature of the city. 


\section{DISCUSSION}

Based on the results of the study, seasonal thermal anomalies of the urban area were outlined. Several seasonal thermal anomalous zones of various types have been identified, such as natural elevations, territories around several large shopping and entertainment centers, industrial zones of a number of enterprises, and areas of thermal pollution by sewage.

In the Zheleznodorozhny district of the city, Pokrovskaya Gora has the highest surface temperature, due to the open grassy slopes and a thin grass cover. Also, a significant excess of surface temperature is observed in the vicinity of the railway station.

On the right bank of Krasnoyarsk city, the maximum temperatures observed in the collection of summer images are in the industrial zone of the city.

In the Sovietsky district of the city, located on the left bank, the maximum temperatures prevail in the industrial zone of the city, as well as in the places of congestion of shopping and entertainment centers. In Figure 5, there are thermal anomalies that correspond to the shopping and entertainment centers: Planeta Shopping Center, Lenta Hypermarket, June Shopping Center, Krasnoyarsk Car dealerships areas (Toyota, Porsche, Audi, Ford), Aviator and Komandor Shopping Centers.

\section{CONCLUSION}

The article presents a technique for monitoring the land's surface temperature based on the data from the 10th band of Landsat 8 . The daily series of thermal images is characterized by high informativity, but the Landsat 8 satellite we are considering does not obtain such images. First of all, we considered the seasonal variability of thermal anomalies, and this problem can be solved with the help of Landsat images. It is possible to note characteristic seasonal differences in thermal radiation of natural and anthropogenic objects.

Summer thermal images are the most informative. In particular, industrial facilities, residential quarters, forests, water bodies and open ground areas can be identified. The use of time series thermal infrared images allows to combine the anomalous features of the territory, observed in its thermal structure, to form the outlines of the main thermal anomalies.

When analyzing the images, thermal anomalies were found on the territory of industrial zones, landscape elevations and anomalies corresponding to the location and form of shopping and entertainment centers. Industrial zones on the left and right bank of Krasnoyarsk city are of special interest sue to their vast area. In the future, the formed thermal anomalies are a valuable material for ecological and geographic studies of the territory.

\section{REFERENCES}

[1] Niclos R., Valiente J.A., Barbera M.J., Caselles V. Land Surface Air Temperature Retrieval from EOS-MODIS Images, IEEE Geoscience and Remote Sensing Letters. (in Russian). 2014. Vol. 11/issue 8. pp. 1380-1384 
[2] Lurie I.K., Kosikov A.G. Theory and practice digital processing images, Nauchniy mir, Russia. 2003. 166p.

[3] Weng, Q.; Lu, D. \& Schubring, J. Estimation of land surface temperature vegetation abundance relationship for urban heat island studies, Remote Sensing of Environment, Elsevier Science Inc. 2004 vol.89. pp. 467-483

[4] Le Hung Trinh, E.A. Terekhin, Danh Tuyen Vu Application of remote sensing in determining land surface emissivity using LANDSAT multispectral imagery (case study: Bac Binh district, Binh Thuan province, Vietnam) Current problems in remote sensing of the Earth from space. (in Russian). 2015. vol. 12/issue 6. pp. 59-68

[5] Khlebopros R.G., Taseiko O.V., Ivanova Yu.D., Mykhaylyut S.V. Ecological essays. Krasnoyarsk: Siberian Federal University, Russia (in Russia). 2012. 130 p.

[6] Giannini M. B., Belfiore O. R., Parente C., and Santamaria R. Land Surface Temperature from Landsat 5 TM images: comparison of different methods using airborne thermal data, Journal of Engineering Science and Technology Review. 2015. Vol.8/issue 3. 2015. pp. 83-90.

[7] P.A. Brivio, G. Lechi, and E. Zilioli, Principi e metodi di telerilevamento, CittàStudi Edizioni, Torino, 2006. pp. 449,479.

[8] Congedo L. Semi-Automatic Classification Plugin Documentation, web resource: www.fromgistors.blogspot.com. 2017. 278 p.

[9] Hrebtov M., Hanjalić K. Numerical study of winter diurnal convection over the city of Krasnoyarsk: Effects of non-freezing river, undulating fog and steam devils, Boundary Layer Meteorology. 2017 pp. 469-495.

[10] Matuzko A.K. Determining water surface temperature by Earth remote sensing data, Regional problems of Earth remote sensing, Materials of IV International Scientific Conference, SFU ISIT. (in Russian). 2017. pp. 271-274. 